Max-Planck-Institut für demografische Forschung

Max Planck Institute for Demographic Research

Konrad-Zuse-Strasse 1 - D-18057 Rostock · GERMANY

Tel +49 (0) 3812081 - 0; Fax +49 (0) 3812081 - 202;

http://www.demogr.mpg.de

MPIDR WORKING PAPER WP 2006-015

JUNE 2006

\title{
Regularities and Peculiarities of Birth \\ Schedules in Industrialized Countries: An Analysis of FFS data
}

René Houle (rhoule@unb.ca)
Vladimir M. Shkolnikov (shkolnikov@demogr.mpg.de)

(C) Copyright is held by the authors.

Working papers of the Max Planck Institute for Demographic Research receive only limited review. Views or opinions expressed in working papers are attributable to the authors and do not necessarily reflect those of the Institute. 


\title{
Regularities and Peculiarities of Birth Schedules in Industrialized Countries: An Analysis of FFS data
}

\author{
René Houle ${ }^{1}$ and Vladimir M. Shkolnikov ${ }^{2}$
}

1

2

\author{
Statistics Canada and Canadian Research Institute for Social Policy, UNB \\ rhoule@unb.ca \\ Max Planck Institute for Demographic Research \\ Shkolnikov@demogr.mpg.de
}

\begin{abstract}
Inter-individual diversity of women according to birth numbers (quantum) and birth spacing (tempo) are important for understanding of fertility regimes. Elsewhere, we have shown that diversity with respect to fertility quantum is increasing from older to younger cohorts. The present study looks at tempo dimension by decomposing the diversity of birth schedules. The data set contains pooled FFS data from 19 industrialized countries and covers 11124 women aged 40-44 at survey. The analyses include descriptive characteristics of birth schedules, their classification by cluster analysis, and the identification of some of the underlying factors by two types of regression analyses. The first of them is a multinomial logistic regression linking types of birth schedules with characteristics of women at the time of interview. The second includes event-history analyses examining the transition to second and third conception (leading to birth), where time since previous birth is combined with the current values of the covariates. Age at first birth is a major component of inter-individual differences in birth schedules and it largely determines their clustering. Distributions of second, third, and fourth births over time since the previous births are very similar to each other. The median length of birth intervals is 3-3.5 years and 75\% of births occur within 5-6 years after the previous delivery. One cluster stands out of this regularity as it is characterized by long last birth interval of about 11 years. Age distributions of fertility for women from this cluster are bimodal and their shape points at unexpectedly "renewed" fertility careers. Additional births produced by the phenomenon compose about $6 \%$ of all births. Regression analyses show that the long last birth interval is associated with new partnerships. Some influence of contraceptive failure can not be excluded, too. More in-depth research is needed to learn about the dynamic factors of birth schedules and particularly about the relationship between entering new partnerships and childbearing.
\end{abstract}




\section{Introduction}

Theories and empirical studies on fertility in the industrialized world focus on the main vector of change, the declining average level of fertility and its determinants. Inter-individual variability plays an instrumental role in this research only in that it is used for identifying the factors influencing the final outcome of births. However, inter-individual diversity in itself is important. In respect to the number of children women have (quantum), inter-individual diversity is increasing in industrialized countries from older to younger cohorts, beginning from the cohorts born in the 1930s-40s (Shkolnikov et al 2004). It means that a kind of "specialization" of population reproduction (Vaupel and Goodwin, 1987, Lutz, 1989) could be emerging among women in a way that different fractions of female population are making more and more uneven contributions to the overall production of offspring.

The present study explores the diversity of birth schedules. We analyze a large set of completed birth histories of women born in the 1950s from 19 industrialized countries. First, we show how chosen countries differ in terms of the amount of variability in the number of given births among women. We then perform the mainstream analysis on diversity along the tempo dimension of fertility (birth schedules). Cluster and regression analyses help us to reveal some regular and peculiar patterns in the variety of birth schedules.

The study relies on pooled FFS data from 19 industrialized countries, which include basic demographic characteristics and histories of births and some other information about women aged 40 to 44 at the moment of surveys. The data largely reflects the fertility experience of the 1980s and the early 1990s. For all countries, the original country-sets are transformed to comply with the weighted distribution of women by number of births by means of random sampling. Then, all country-sets are pooled into one data set with about 12 thousand observations. Country-specific fractions of women vary from 287 in the Czech Republic to 1,666 in the USA. For general tabulations and descriptive statistics, the full data set is used accounting also for individual weights. To avoid over- or under-representation of countries in the cluster analysis, we use a reduced data set with a relatively equal representation of countries by country fractions varying from 300 to 500 women (400-500 for most of the countries).

\section{Diversity of birth schedules}

Figure 1 shows the birth trajectories of US and Bulgarian women aged 40-44 in the mid-to-late 1990s. The birth trajectories run across years of life from age 15 to age 45 . The intensity of gray and the patterns within horizontal bars in the figure correspond to periods of life with no, one, two, three, four, and 5+ children. The trajectories are sorted in ascending order of ages at first, 
second, third, fourth, and fifth births. The left panel clearly contrasts with the right one. US women experience much more variability than their Bulgarian counterparts in respect to both quantum and tempo dimensions. American women are much more variable in respect to the number of children they have. Many of them remain childless, but many other have three or more children. In Bulgaria, a greater proportion of women take part in reproduction and their contributions are more even, with the majority giving two births. Importantly, the ages at birth in the USA are also much more variable than those in Bulgaria. This is reflected in the different shapes of the two pictures in respect to the age of entrance into motherhood and the ages of giving subsequent births.

\section{Figure 1. Birth trajectories of two hundred women randomly selected from the US and the Bulgarian birth cohorts of 1954-56, FFS data.}
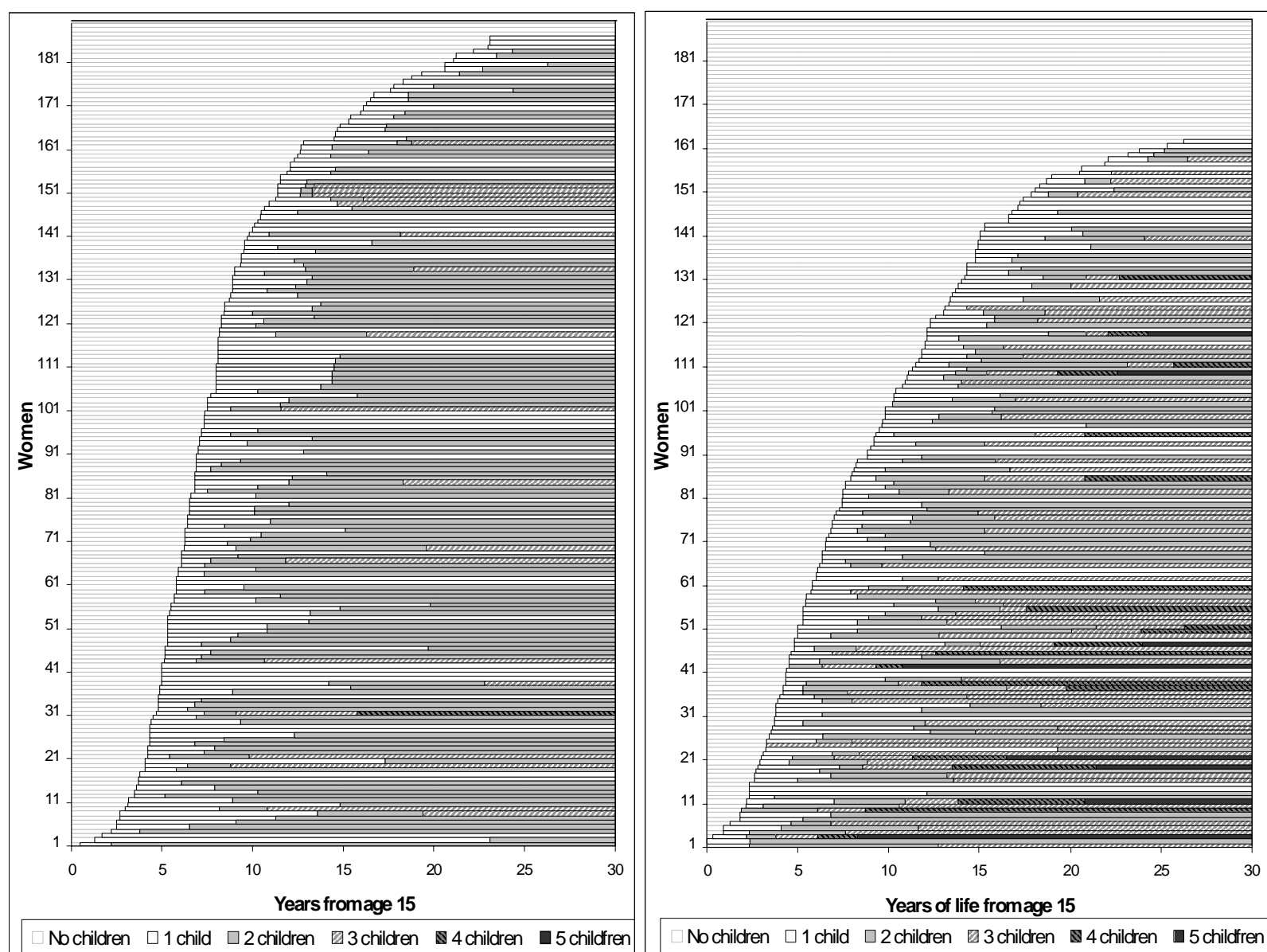

Table 1 presents some characteristics of the birth histories of women aged 40-44 in the FFS surveys in 19 industrialized countries, included in most of our further analyses. It shows the percentages of women according to the number of births they have given, average completed fertility (CF), the average inter-individual difference in the number of births (AIID), and the concentration ratio equal to a ratio of the two latter indicators CR=AIID/CF (see Shkolnikov et al., 2004, for more details on CR and AIID). CF varies from 1.7 in Switzerland and Bulgaria to more than 2 in France, Poland, Norway, and New Zealand. Table 1 also shows high proportions 
of final parity of 2 children in some countries. This is especially true for countries of the former socialist block (except Poland) but also for Italy, Spain, and Portugal. The countries in Table 1 are sorted in descending order of CR (called also Gini coefficient). Its highest values are observed in the USA, Canada, and Switzerland, whereas the lowest values are seen in Eastern European countries and Norway. The highest AIID values, about 0.7 children, are observed in the USA and Canada while the lowest AIIDs, close to 0.4 children, are observed in Slovenia and Bulgaria.

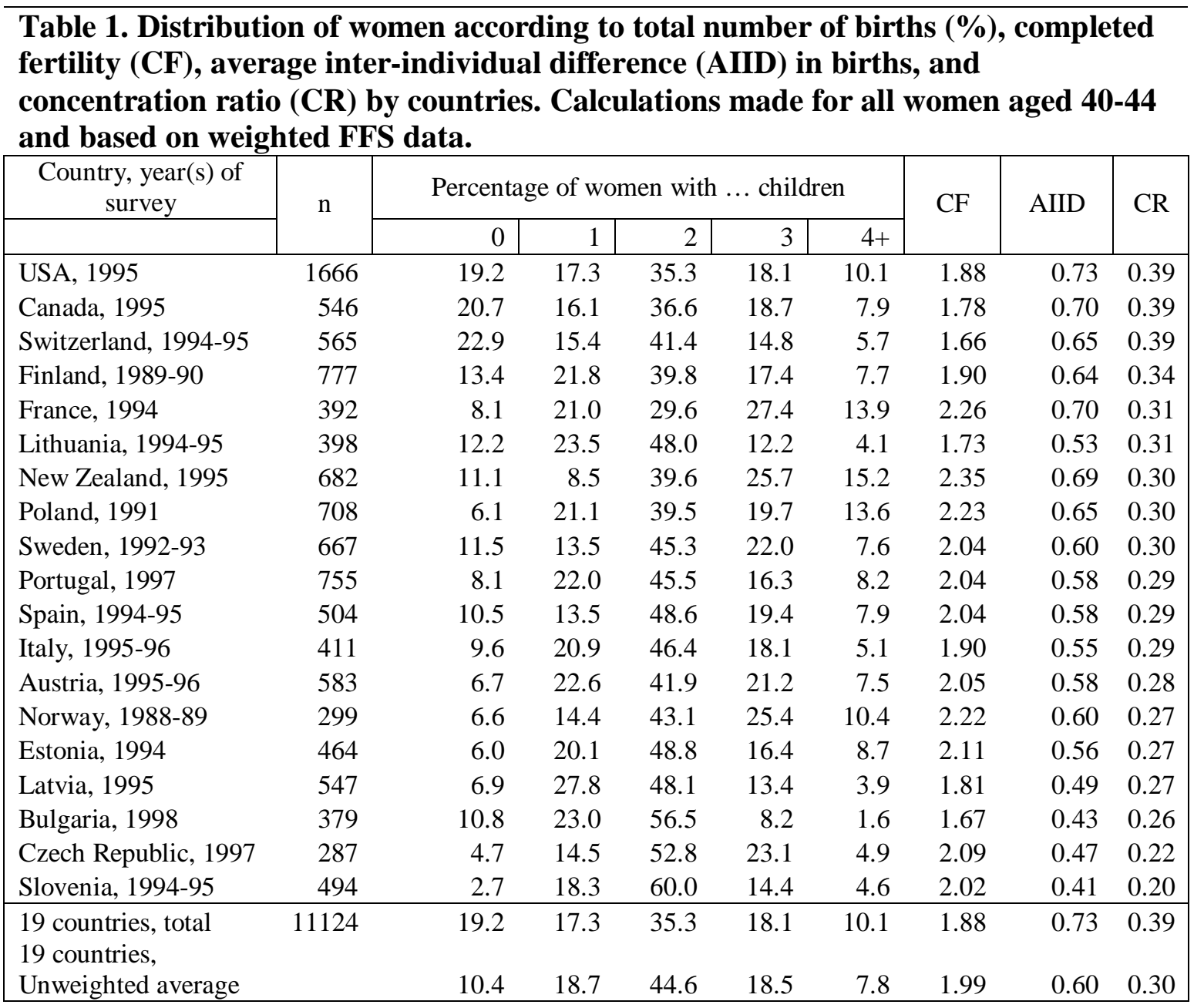

Countries with a high variability in the number of children, such as the USA, Canada, Switzerland, and Finland show a significant contrast between large numbers of women with no children and numerous women with $3+$ children, whereas in countries with low variability in the number of children (Eastern Europe), childlessness is generally low and large fractions of women have two children.

Further considerations will be devoted to the exploration of the tempo component in the interindividual diversity of birth schedules. The analysis will include their descriptive characteristics, their classification by cluster analysis, and the identification of some of the underlying factors 
by two types of regression analyses. The first of them will be a multinomial logistic regression based on completed birth schedules and characteristics of women at the time of interview. The second consists of an event-history analysis examining the transition to second and third conception (leading to birth) where time since previous birth is combined with current values of risk factors.

\section{Birth intervals}

Preliminary analyses (not shown here) on the pooled data revealed the following retrospectively observed and expectable regularities across the birth schedules. First, there is a higher total number of births that is associated with an earlier beginning of childbearing, and for every birth order, the age at birth is lower in women with a higher total number of births. Second, the average length of the birth interval diminishes as the total number of birth increases.

Table 2 and Figure 2 portray the birth intervals for women aged 40-44 in the 19 countries. These data do not show much variation across the countries, especially for the mean age at first birth (a coefficient of variation of only 4\%). The variability across the countries increases with birth order but remains relatively low. In total, women aged 40-44 with parities 2 to 4 reach their corresponding final number of births by age 36.6 years on average. 


\begin{tabular}{|c|c|c|c|c|}
\hline & Age at first birth & $\begin{array}{l}\text { Length of } \\
1^{\text {st }} \text { interval }\end{array}$ & $\begin{array}{l}\text { Length of } \\
2^{\text {nd }} \text { interval }\end{array}$ & $\begin{array}{l}\text { Length of } \\
3^{\text {rd }} \text { interval }\end{array}$ \\
\hline Czech Republic & 22.6 & 3.51 & 5.84 & 4.99 \\
\hline Slovenia & 22.7 & 4.17 & 4.82 & 5.32 \\
\hline Bulgaria & 23.0 & 3.94 & 4.50 & 5.67 \\
\hline Estonia & 23.3 & 4.08 & 5.40 & 4.07 \\
\hline Portugal & 23.7 & 4.34 & 4.35 & 3.17 \\
\hline USA & 23.7 & 3.80 & 4.11 & 3.70 \\
\hline Austria & 23.8 & 3.80 & 4.67 & 4.24 \\
\hline Poland & 23.9 & 3.68 & 4.51 & 4.23 \\
\hline Latvia & 23.9 & 4.48 & 5.37 & 3.96 \\
\hline Sweden & 24.1 & 3.96 & 5.38 & 5.02 \\
\hline Norway & 24.1 & 3.33 & 4.11 & 4.72 \\
\hline Lithuania & 24.1 & 4.32 & 5.75 & 4.70 \\
\hline France & 24.2 & 4.24 & 4.38 & 3.83 \\
\hline Finland & 24.3 & 3.83 & 5.49 & 5.05 \\
\hline New Zealand & 24.4 & 3.04 & 3.81 & 3.66 \\
\hline Canada & 24.5 & 3.15 & 4.20 & 3.53 \\
\hline Italy & 24.6 & 4.16 & 4.67 & 5.31 \\
\hline Spain & 25.2 & 3.87 & 4.58 & 3.63 \\
\hline Switzerland & 26.9 & 3.13 & 3.62 & 3.13 \\
\hline 19 countries, total & 24.1 & 3.83 & 4.57 & 4.11 \\
\hline $\begin{array}{l}19 \text { countries, unweighted } \\
\text { average }\end{array}$ & 24.1 & 3.83 & 4.71 & 4.31 \\
\hline Standard deviation & 0.94 & 0.43 & 0.65 & 0.77 \\
\hline Coefficient of variation & 0.04 & 0.11 & 0.14 & 0.18 \\
\hline
\end{tabular}

Figure 2. Mean age at first birth and mean lengths of birth intervals (in years) in 19 countries for women aged 40-44.

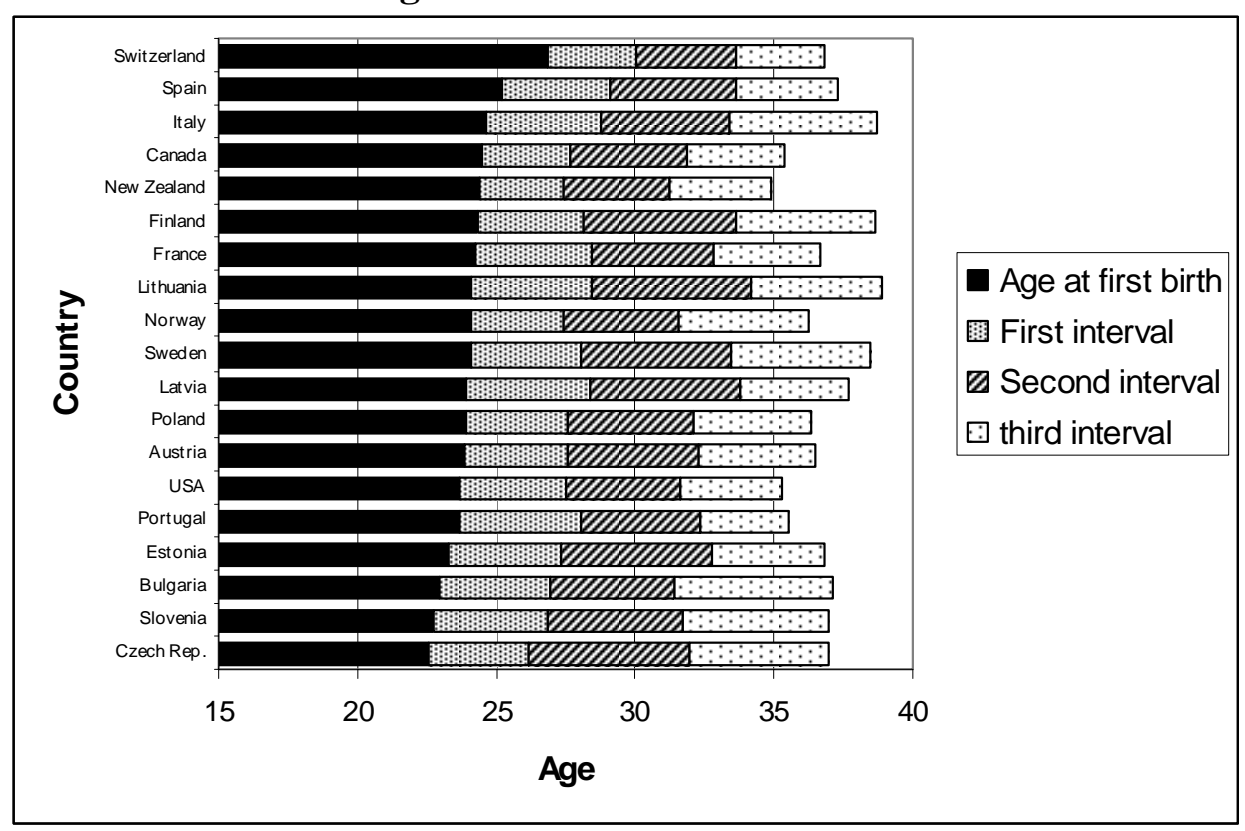

Figures 3 and 4 display the distributions of birth intervals by their duration across women and the respective percentiles for the same 19 countries pooled together with nearly an equal 
representation of each country. The similarity of the distributions for different parities is striking. It seems as if once started, fertility follows an internal schedule. After the first, second, and third births, the next births are highly concentrated within a narrow range of 1 to 3 subsequent years. Figure 4 shows that the median value of the distribution is 3 years for the first and the third birth intervals, and 3.5 years for the second birth interval. Of the births, $75 \%$ take place no later than within 5-6 years after the previous delivery. After 8 years, between $85 \%$ and $90 \%$ of next births occur to these women.

Figure 3. Distributions of the first three birth intervals by length for the first three birth intervals.

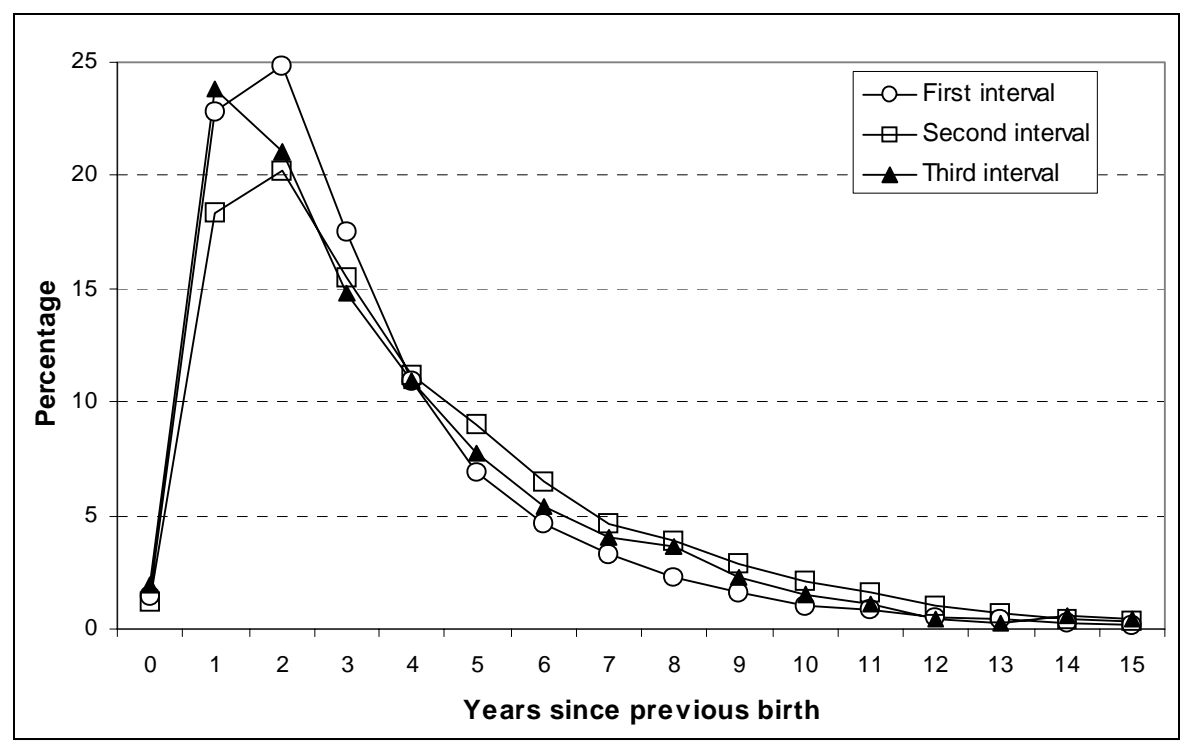

Figure 4. Selected percentiles of birth interval distributions by length for the first three intervals.

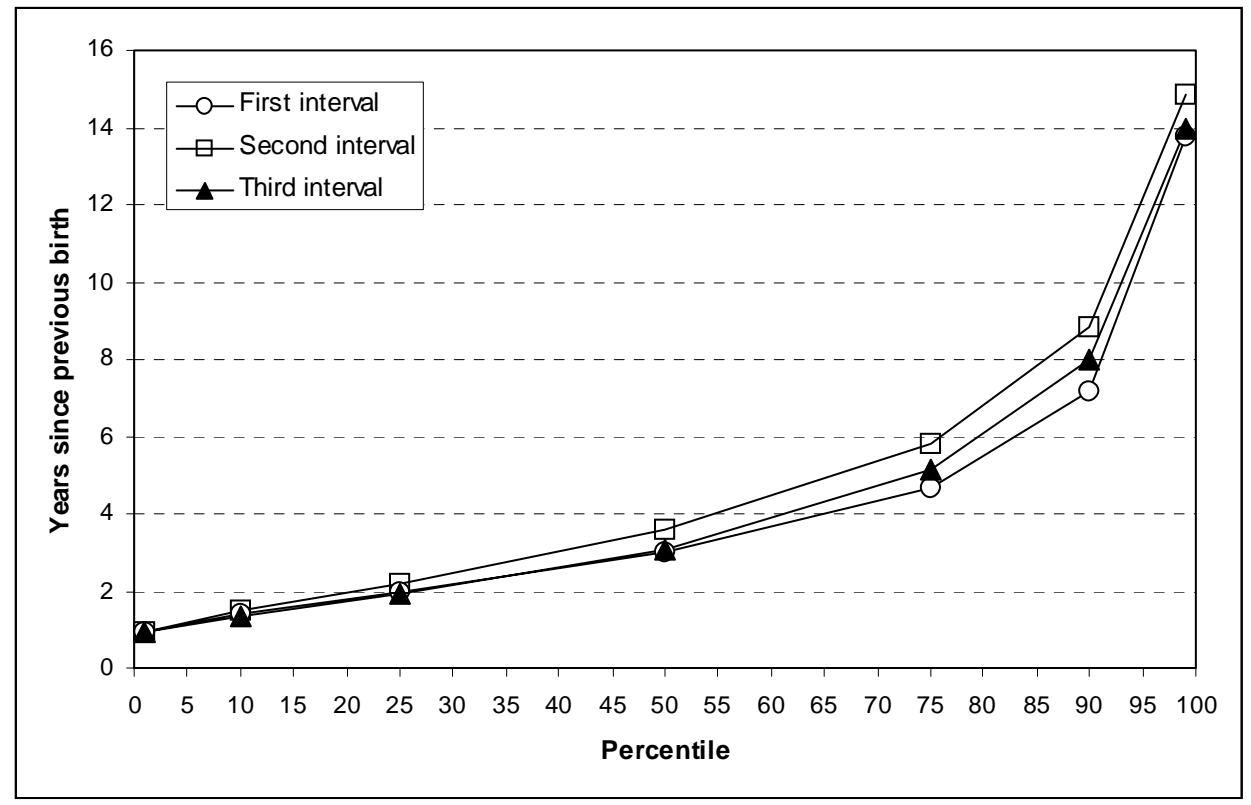

\section{Types of birth schedules}

These results point at stability in the birth intervals across the countries, but also across the women studied, the majority of who tend to have the next child within a few years after the 
previous one. Considerable variability, however, exists across these women, as some of them have a next child after a much longer time period. Our question is whether the latter pattern equally affects all women irrespective of their fertility pattern reflected by age at first birth and/or length of previous birth interval(s), the social or contextual characteristics (the education level and country of residence, respectively), or whether it correlates with some of these characteristics.

In this section, we identify the major types of birth schedules among women.

$\mathrm{K}$-means cluster analysis of birth schedules is applied to identify these types (see Annexes 1 and 2 ). The calculations are made on the pooled data with an almost equal representation of countries. Simple Euclidian metrics is used for measuring the distances between individual birth schedules (e.g. the sequences of ages at birth). Thus, for each number of births (from 2 to 4 ), the women are classified into cluster-groups according to similarity in spacing of birth expressed by ages at birth. The number of clusters $(\mathrm{K})$ for each total number of births has to be chosen according to certain statistics (see Annex 1 for more details). The final number of clusters is five for schedules with 2 and 3 births and four for schedules with 4 births. In order to ensure that the clustering solution corresponds to the global minimum of the within-cluster variance $\left(S S_{\text {within }}\right)$, the clustering routine has to be repeated 100 times (see Annex 2 for more details). All calculations are made with Stata 7 (StataCorp., 2001).

Figure 5 shows the mean birth schedules for every cluster for women with two, three, and four children. Table 3 provides simple descriptive statistics of the clusters. The clusters are ordered by mean age at first birth, so that Cluster 1 has the youngest mean age at first birth. For each cluster in Figure 5, we show the mean age at first birth (the origin of the black bar) and then the mean age at second birth. The birth intervals correspond to the lengths of the bars. For example, for women with 2 births from Cluster 1, the mean age at first birth is 19.8, the mean age at second birth is 22.9 , and the mean length of the first birth interval is thus 3.1 years.

In general, these results reveal that age at first birth plays a prominent role as a central determinant of clustering. At every level of total completed fertility, clusters markedly differ from each other due to age at first birth. The range of variation in age at first birth is impressive, especially when taking into account that every cluster represents substantial fractions of women (no less than 9\%). Indeed, the mean age at first birth differs from 19.8 years (Cluster 1) to 32.3 (Cluster 5) among women with two children and from 19.2 years (Cluster 1) to 29.2 (Cluster 5) among women with three children. The fifth clusters, of late motherhood, constitute $10-13 \%$ of all women with two and three children, respectively. 
Among women, with each number of births one cluster clearly differs from the others. This special cluster has Index 2, which means that it has the second lowest mean age at first birth. The cluster is peculiar due to a very long last birth interval when compared with the other clusters within the same total number of births. The special cluster is not a small one. It contains $9.3 \%$ of all women with 2 births, $14 \%$ of women with 3 births and $20 \%$ of women with 4 births (Table 3). For women with two children, the only birth interval of Cluster 2 is almost 11-year long, while it is no longer than 4 years in the other clusters. For women with three children, the second interval of Cluster 2 exceeds 11 years, which contrasts with a mean length of about 4 years of other clusters. A similar pattern is found for women with four children, but the difference between the second cluster and the other clusters is smaller.

Figure 5. Mean birth schedules by clusters for women with two, three, and four children. Results of K-Means cluster analysis.
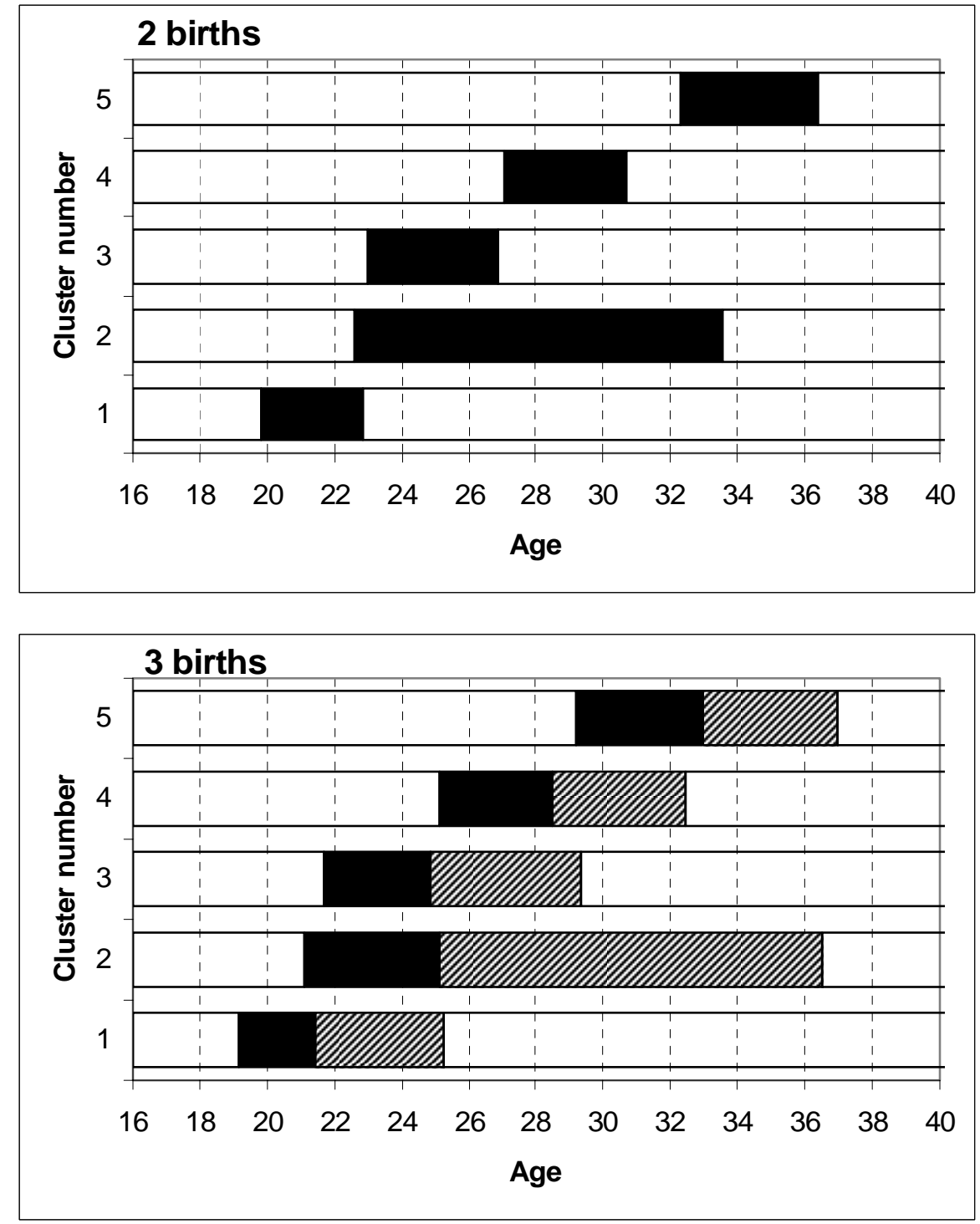


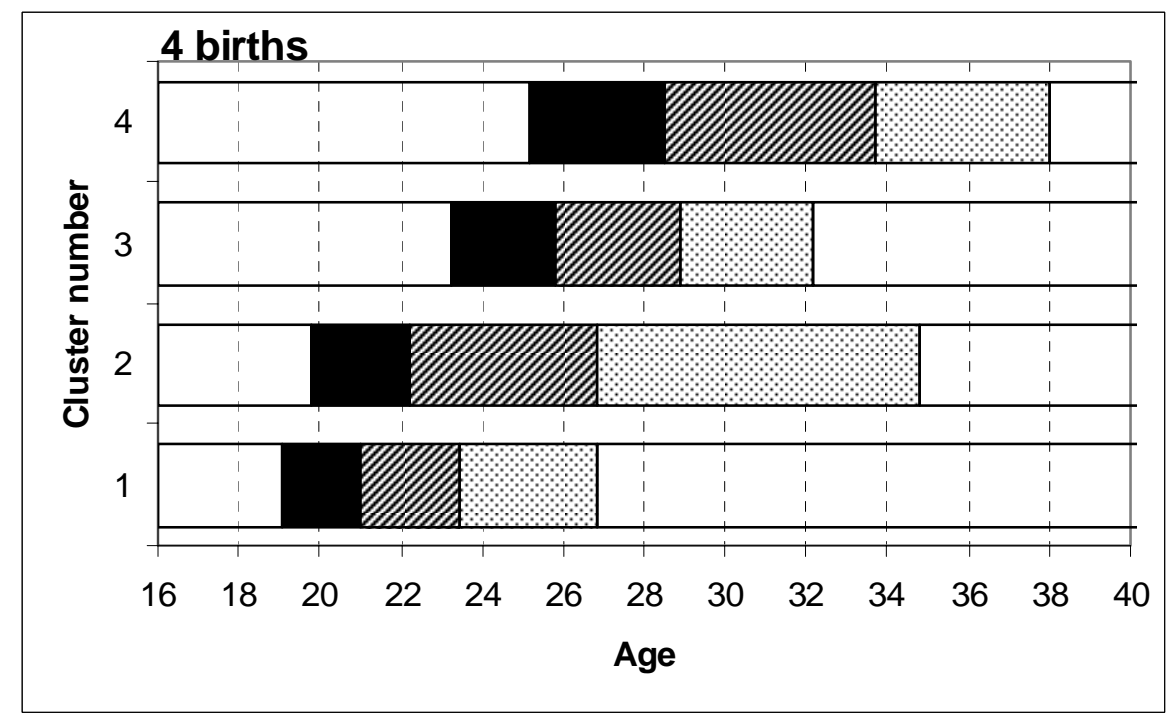

Another interesting point is the young age at first birth of women in Cluster 2. For women with two and three children, the mean age at first birth for Cluster 2 is about the same as for the next cluster, Cluster 3. The ages are 23 and 21 years for women with two and three children, respectively. As to women with four children, the mean age at first birth in Cluster 2 is similar to that in the first cluster and is equal to 19 years. Interestingly, women in Cluster 2 enter motherhood early, but they finish their reproductive activity quite late, in fact, almost as late as the late beginners from Clusters 4 and 5. This pattern looks striking in the case of women with three children (Table 3). The result is that women in the special cluster have a long childbearing span that lasts about 15 years for those with three and four given births, whereas the reproductive life of women from other clusters lasts less than 10 years. This difference is even larger for women with two children: 11 years in Cluster 2 vs. less than 4 years in the other clusters.

One can also learn more about the clusters by looking at the age-specific fertility rates for the respective groups of women according to completed fertility and cluster number. This is done in Figure 6, which presents types of fertility age curves. We use the same numbering of clusters as in Figures 5 and Table 3. In Figure 6, Cluster 2 corresponds to the bold black curves. For every total number of births, Cluster 2 is characterized by a very peculiar bimodal fertility curve. It looks like a split in the curve in two parts, as if childbearing had started over and the respective women had gone through a second fertility career. For women with 2 births, the Cluster 2 fertility curve is divided exactly into two sub-curves, with a breaking point at age 28 . The age intervals corresponding to these two parts (i.e. ages 14-28 and 28-44) produce exactly one child each. For women with 3 births, the Cluster 2 curve is split at age 30. The first age interval (ages 
14-30) gives two children, while the second one (ages 30-44) gives one child. For women with 3 births, the split is less pronounced and does not correspond to integer numbers of given births.

Figure 5 tells that part of women begin a renewed fertility career, something that could not be expected given the prior history of births. One can try to estimate a number of children contributed to the overall outcome of offspring by the phenomenon. The number can be estimated as the difference between the actual number of children produced by a female cohort minus the number of children which would have been observed in absence of the second fertility career in the special cluster (Approach 1). It is possible also to calculate the change in the offspring that would have taken place if the women from Cluster 2 had been redistributed among other clusters (approach 2). Both calculations return about the same proportion of additional births equal to $5.7 \%$.

Table 3. Characteristics of clusters for women aged 40-44 who have given birth to two, three, and four children.

\begin{tabular}{|c|c|c|c|c|c|}
\hline \multirow{2}{*}{$\begin{array}{c}\text { Number } \\
\text { of births, } \\
\text { cluster } \\
\text { number }\end{array}$} & \multicolumn{2}{|c|}{ Cluster size } & \multirow{2}{*}{$\begin{array}{l}\text { Mean age } \\
\text { at first } \\
\text { birth }\end{array}$} & \multirow{2}{*}{$\begin{array}{c}\text { Mean age } \\
\text { at last } \\
\text { birth }\end{array}$} & \multirow{2}{*}{$\begin{array}{c}\text { Mean } \\
\text { birth } \\
\text { interval }\end{array}$} \\
\hline & $\mathbf{N}$ & $\%$ & & & \\
\hline \multicolumn{6}{|c|}{ Women with 2 births } \\
\hline 1 & 871 & 22.7 & 19.8 & 22.9 & 3.1 \\
\hline 2 & 356 & 9.3 & 22.6 & 33.5 & 10.9 \\
\hline 3 & 1,343 & 35.0 & 23.0 & 26.9 & 3.9 \\
\hline 4 & 846 & 22.1 & 27.0 & 30.7 & 3.6 \\
\hline 5 & 420 & 10.9 & 32.3 & 36.4 & 4.1 \\
\hline Total & 3,836 & 100.0 & 24.1 & 28.5 & 4.3 \\
\hline \multicolumn{6}{|c|}{ Women with 3 births } \\
\hline 1 & 347 & 21.5 & 19.2 & 25.2 & 3.0 \\
\hline 2 & 226 & 14.0 & 21.1 & 36.5 & 7.7 \\
\hline 3 & 470 & 29.1 & 21.7 & 29.4 & 3.8 \\
\hline 4 & 365 & 22.6 & 25.1 & 32.5 & 3.7 \\
\hline 5 & 209 & 12.9 & 29.2 & 37.0 & 3.9 \\
\hline Total & 1,617 & 100.0 & 22.8 & 31.1 & 4.2 \\
\hline \multicolumn{6}{|c|}{ Women with 4 births } \\
\hline 1 & 121 & 26.2 & 19.1 & 26.8 & 2.6 \\
\hline 2 & 94 & 20.3 & 19.8 & 34.8 & 5.0 \\
\hline 3 & 147 & 31.8 & 23.2 & 32.2 & 3.0 \\
\hline 4 & 100 & 21.6 & 25.2 & 38.0 & 4.3 \\
\hline Total & 462 & 100.0 & 23.2 & 32.2 & 3.0 \\
\hline
\end{tabular}


Figure 6. Age-specific fertility rates by number of birth and cluster.
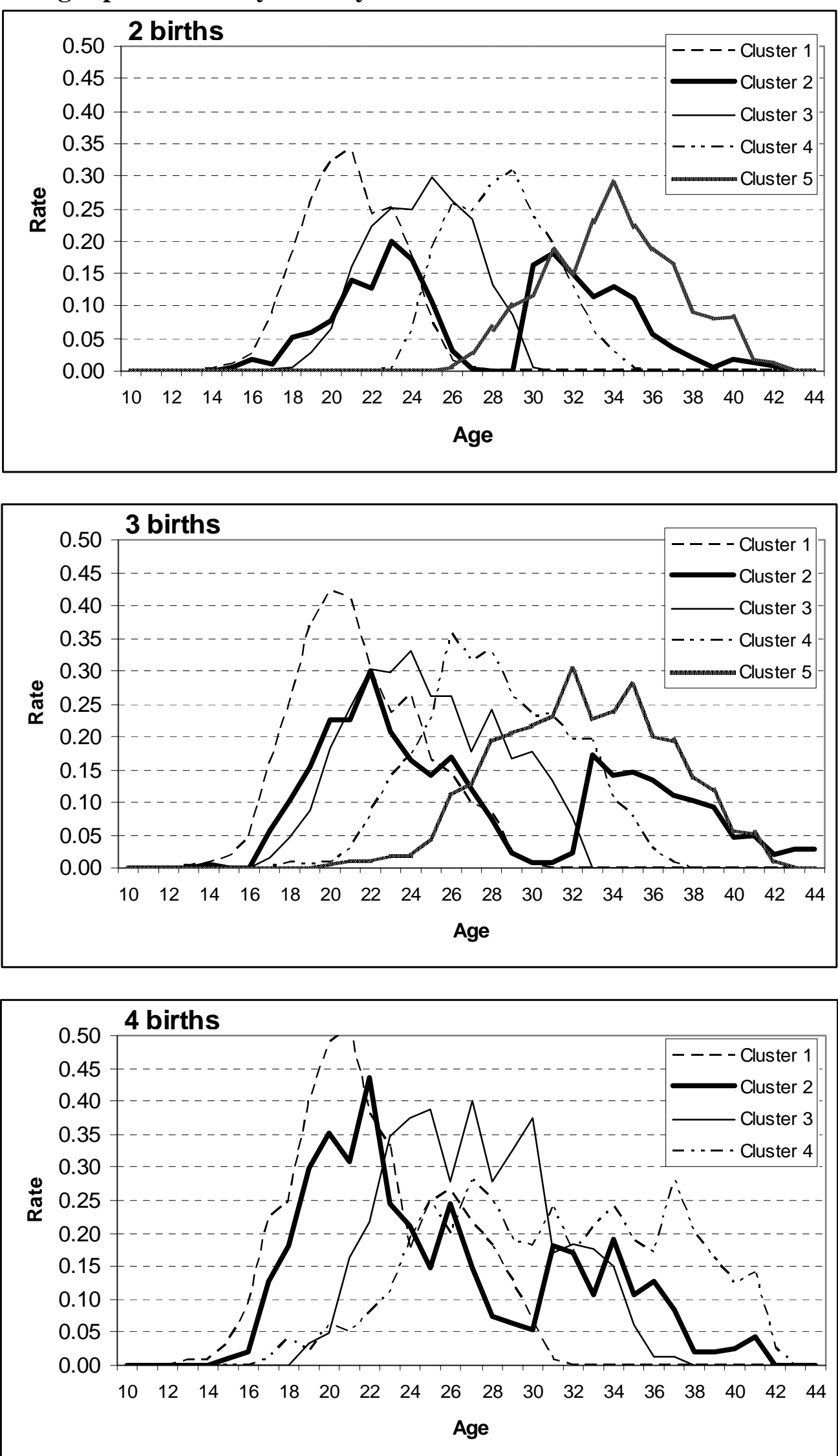


\section{What stands behind clusters}

The previous section has shown two components of diversity in women's birth schedules. There is a mainstream dependence of clustering on age at first birth and also a special cluster with a very long interval preceding the last birth.

We can think of at least three hypotheses that could help to explain this last long birth interval. The first one is the remarriage hypothesis as proposed by Thornton (1978). The basic argument is that in certain contexts (low and planned fertility, rapid remarriage after dissolution), there exists a norm or the desire that each marriage brings its own child. Having a child is a sign of commitment to the new union (Vikat et al. 1999). A second hypothesis relates long birth intervals to the fact that working women try to minimize career interruptions. This view, however, is contested by the exact opposite contention, namely that working women compress their fertility in order to minimize the time they have to spend outside the labor market (Ram \& Rahim 1993). A third hypothesis is simply to consider that long birth-intervals are consequences of contraception failures. But one may wonder how the high proportion of failures $(11 \%$ of our women with parities 2-4 are in Clusters 2) could have taken place in settings of high fertility control, where for the most part contraception is widespread, be it in the form of modern contraception (as in the West) or in the form of induced abortion (as in the former socialist states). Nevertheless contraception failure such as this is not incompatible with the remarriage effect since remarriage increases sexual intercourse. According to this hypothesis, both effects are mixed and very difficult to disentangle without the appropriate data.

\section{Multinomial logistic regression.}

Below, we present the results of a multinomial logistic regression that relates being in any one of the five clusters (for women with two and three births, separately) to education, the number of marriages ever contracted, and to the individual's region of residence.

The dependent variable is the probability of being in one of the five clusters. Cluster 1 , characterized by the youngest age at first birth, is taken as the reference cluster. The first covariate is educational attainment at the moment of survey. We have defined only two educational level values due to problems we faced when trying to set up a more detailed common categorization for all countries. (We actually had to exclude from the regression two countries because they deviate in the educational structures of women: Sweden and Lithuania). The two values of educational level are low and high education. Low education is defined by any kind of education below post-secondary. High education is defined as any post-secondary education, including university. 
The number of marriages is given by Question 202 in the international version of the FFS questionnaire. Question 207 asks for the number of partnerships, but unfortunately not all countries included it in their surveys. The ideal source as to marriage and partnership would have been complete partnership histories, but they were not used because of non-comparability (or their absence) in some countries. This applies to Portugal, Bulgaria, and Poland (Festy \& Prioux, 2001). The five regions used to define the regional variable are groups of countries based on geographical or cultural proximity (Table 4).

Table 4. Regions used in multinomial logistic regression

\begin{tabular}{ll|ll}
\hline Region & Country & Region & Country \\
\hline \multirow{2}{*}{ West } & Austria & East & Bulgaria \\
& France & & Czech Rep. \\
& Switzerland & & Poland \\
& Italy & & Slovenia \\
South & Spain & Baltic & Estonia \\
& Portugal & & Latvia \\
& Finland & Lithuania \\
& Norway & Overseas & Canada \\
& Sweden & & USA \\
& & & New Zealand \\
\hline
\end{tabular}

The results of the regressions are presented in Tables 5. The upper panel of Table 5 refers to women with two children and the lower panel refers to women with three children. The same calculations were also made for women with four children, but they are not shown here.

One of the points to note is the effect of having a high level of education. Our results clearly show a strong correlation between an increased age at first birth and higher education, a relationship that has been considered in great detail elsewhere (Blossfeld and Huinink 1991). The higher the age at first birth (that is, the higher the cluster number), the higher the relative risk of the higher educated of being in higher clusters (in particular in the last two clusters).

Education does not affect in a specific manner the propensity of being in Cluster 2. For women with two children, the effect of high education is greater than for Cluster 3, but this is not the case for women with three and four children for whom the effect of having high education increases continuously with the cluster number.

Having been in two or more marriages increases the risk of being in Cluster 2 for women with two children. A similar pattern is found for women with three and four children, although the coefficients are not statistically significant. These results partially support the remarriage hypothesis. In respect to the region of residence, the result is less easy to interpret. 
Here, the level of completed fertility plays a stronger role. For women with two children, one first can see three types of regions in terms of cluster distribution. In the Southern region, formed by Italy, Spain, and Portugal, the risk of being in Cluster 2 is increased in comparison with the rest of the clusters, all of which have equal relative risk ratio values of about 1 . The rest of the counties (except the countries of the region West, which is taken as the reference category) exhibit a very pronounced effect of age at first birth on the propensity of being in one of the five clusters. In the case of the Nordic, East, and Baltic regions, we clearly see that the higher the cluster number is, the lower is the propensity of being in the cluster (all relative risk ratios have values below 1). The pattern for the overseas region is different and the relation takes the form of a U-shape: the risks of being in a cluster are higher at both extremes, with very low risks of being in Cluster 2.

For women with three children, two specific situations can be distinguished. On the one hand, the risks of being in Cluster 2 are very high for the Baltic region and they are low for the overseas region. On the other hand, there is a general tendency of a decreasing propensity of being in Cluster 4 and 5 in all regions but that of the South. Even though most coefficients for women with four children in Table 6 are not statistically significant, one can note that the situation is about the opposite for women with two and three children: the risks of being in clusters increase with age at first birth, or at least they do not diminish. This is consistent with Table 2 and Figure 3 suggest that the relation between age at first birth and the final fertility outcome becomes weaker at high parities. 
Table 5. Results of multinomial logistic regression for women with two and three children.

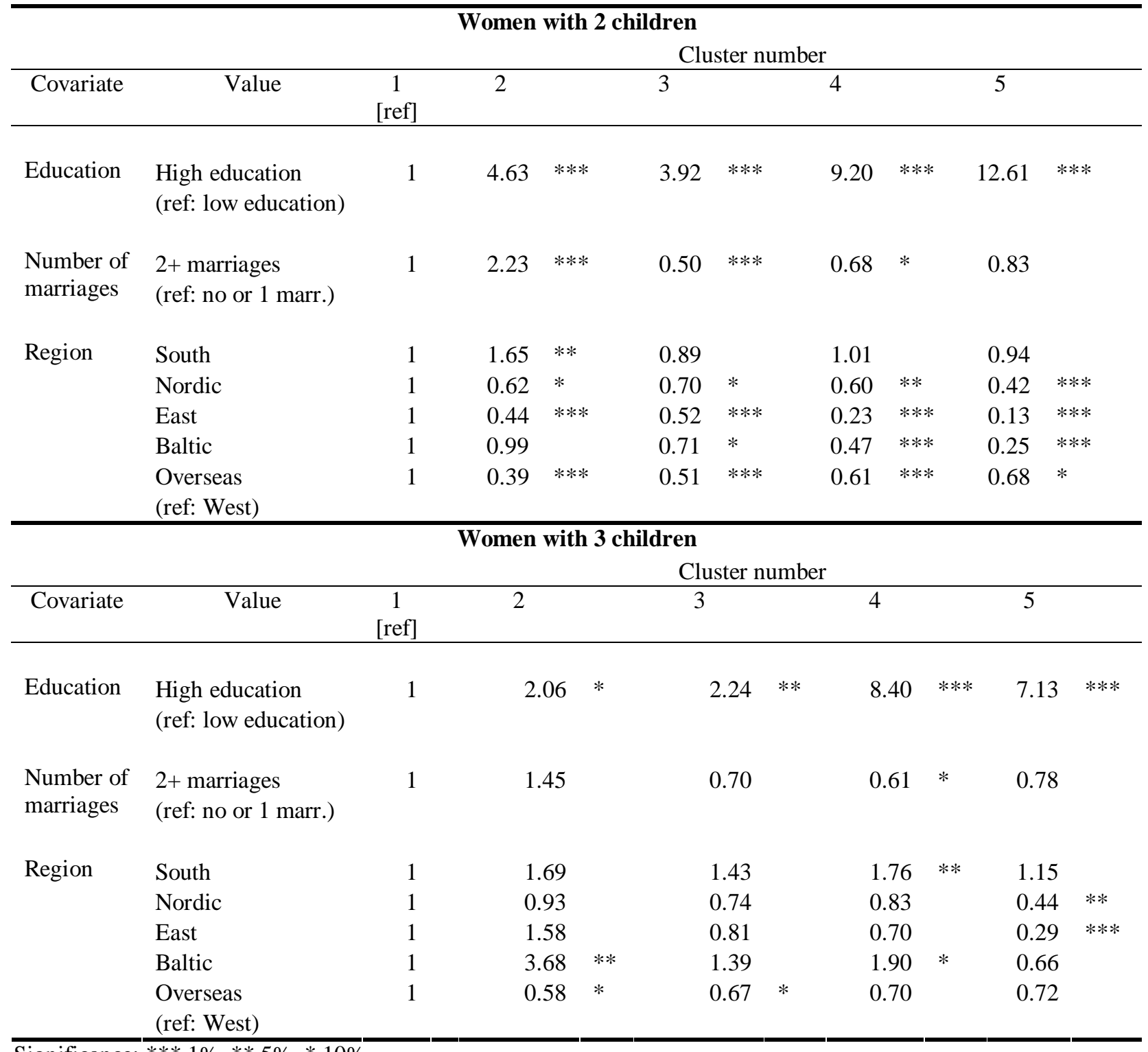

Significance: $* * * 1 \%, * * 5 \%, * 10 \%$

\section{Event-history analysis.}

The mlogit regression directly linked the five types of completed birth schedules (as reflected by the clusters) with explanatory variables. This static analysis has certain limitation since it uses only endpoints of dynamic histories of partnerships and educational careers (e.g. partnership or education status at the time of survey). For education, the problem is not so serious since a vast majority of women experience first childbirth after (or close to) the age of reaching their highest educational level. Thus, birth intervals preceding the second and subsequent birth cover a lifetime with an educational level that is completed or almost completed and thus unchangeable. This is not true for the partnership status since it can be changing throughout the life-course. Therefore, the question remains whether the association between having been remarried and the long last birth interval (Cluster 2) in Table 2 is causal in nature. 
To examine whether second and subsequent marriages and cohabitations increase the risk of second and third birth over the life course, we apply an event history analysis. First, we reshape the data into a longitudinal format. The lifetime of every woman is split into two-year segments that represent the baseline, the number of years since previous birth. The current values of the time-varying covariates (e.g. education and the marital/cohabitation status) are derived from the FFS data. The regression model connects the time-varying hazard of the fertility event of interest (e.g. second or third birth) with a piecewise constant baseline hazard $h_{0}(t)$ and an exponential risk function. The latter determines the effects of time-varying and time-constant covariates on the hazard of second or third births:

$h(t)=\exp \left[\ln h_{0}(t)+\beta_{P}\right.$ Partnership $(t)+\beta_{E} E d u c(t)+\beta_{A}$ AgeFirstBirth $+\beta_{C o}$ Cohort $+\beta_{C n}$ Country $]$.

Table A3-1 in Annex 3 shows the baseline hazard across two-year time segments within the first (between first and second birth) and the second (between second and third birth) birth intervals as well as the relative risks (exponentiated beta-coefficients) by partnership and educational statuses. Most importantly, the results suggest a statistically significant elevation of second birth risk due to re-marriage and a statistically significant elevation of risk of third birth due to both re-marriage and new cohabitation (Figure 7).

Figure 7. Relative risks of second and third birth (conception) by partnership status ${ }^{\#}$.

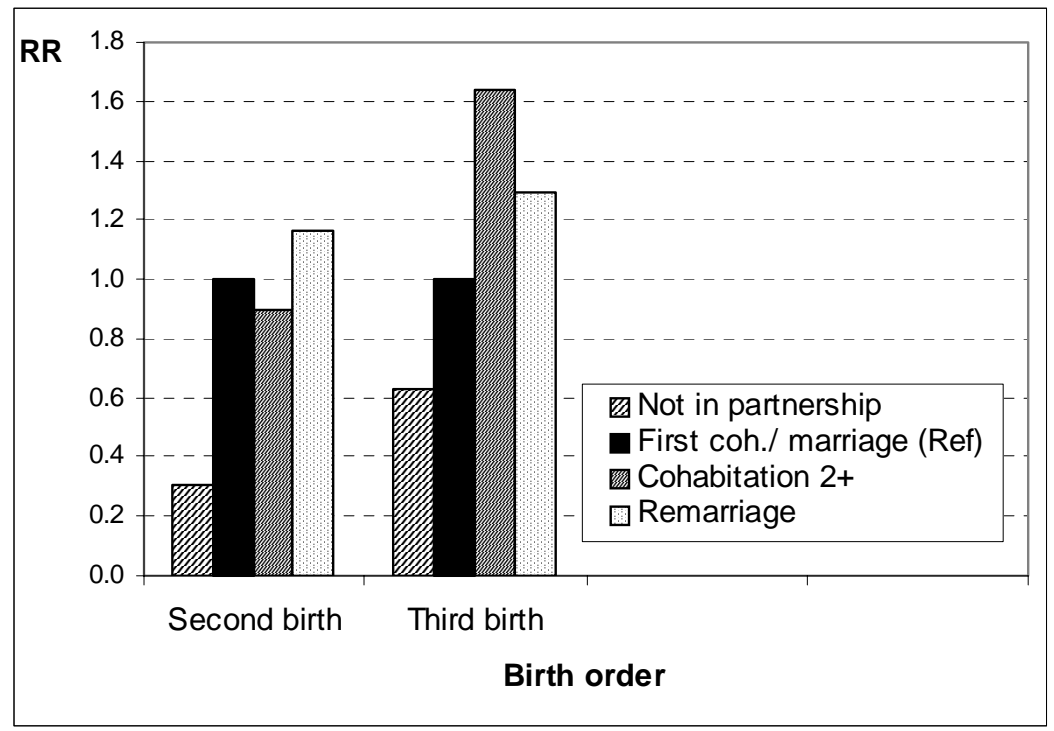

\# All effects shown are statistically significant (at at least $\mathrm{p}<0.05$ )

This points to the possible influence of a "new union commitment effect". A more precise event-history model allows examining the link between the long last birth interval and the status of being in a new partnership. The model includes an interaction term presenting all combinations of partnership categories with the baseline hazard across two-year time segments: $h(t)=\exp \left[\beta_{P \times H}(\right.$ Partnership $(t) \times t)+\beta_{E} E d u c(t)+\beta_{A}$ AgeFirstBirth $+\beta_{C o}$ Cohort $+\beta_{C n}$ Country $]$. 
Table A3-2 in Annex 3 presents the relative risks across the categories of the interaction term and education. This table and Figure 8 make it clear that re-marriage and/or new cohabitation lead to an increase in relative risks of second and third birth in 6-8 years time after the previous birth.

Figure 8. Effect of partnership status in interaction with the baseline (time since previous birth) on fertility (conception) by order of birth.
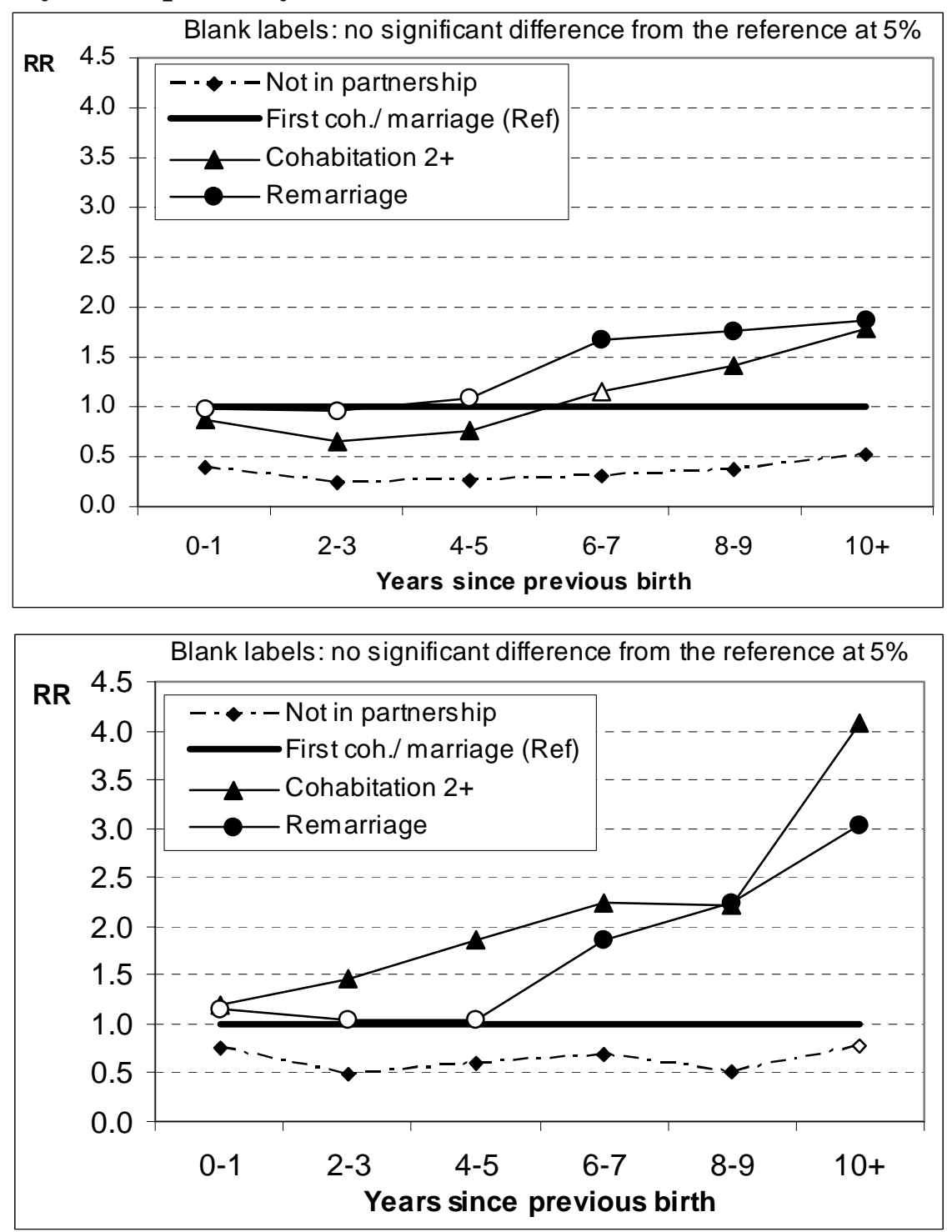

\section{Summary of findings and discussion}

Our analysis of variability aimed at answering the questions of how women and families differ from each other according to fertility or family processes. By the same token, it sought to decompose and explain this diversity. We already know that females of the cohorts born in the 1930s-40s tended to be more diverse in respect to the number of children women have (Shkolnikov et al., 2004). In the beginning of this study, we have shown that regions and countries are characterized by very different degrees of diversity of women in respect to the 
number of children they have. In addition to the quantum dimension, it is interesting to analyze the tempo dimension, something that this study addressed as it is mainly an investigation of inter-individual variability in the timing of births.

We analyzed the diversity of individual birth schedules in 19 countries that participated in the 1990s in the FFS project. Methodologically, this paper has some relation with studies analyzing individual life trajectories, such as the study of job careers by Solis and Billari (2002). The fact that birth histories are chains of repeatable and uniform events allows applying a simple cluster analysis for their classification. In general, our work shows the relevance of examining complete birth schedules as sequences of demographic events observed from the very beginning to the very end of the reproductive period. For example, it is well known that a young age at first birth increases the transition to second birth. It appears, however, that the more women progress in their childbearing experience (at least up to the fourth birth), the less this relation holds. The relation is not invalidated, but it must be placed in an adequate context.

It has been known for some time that the succession of births in the female population follows a clear pattern, to the point that some authors even speak of an "engine with its own momentum" determined by early motherhood and education (Rodríguez et al. 1984). Our findings are consistent with this concept. It was shown that birth schedules function in the sense used by Rodríguez et al (1984): Once the childbearing process has begun, it follows a relative stable path, characterized by relatively stable birth intervals conditioning both age at first birth and the total number of children born. Individual-level distributions of women by length of birth intervals are almost the same for women with different total numbers of children. For each final parity, women mostly differ in age at first birth, and less so in the length of birth intervals. A formal cluster analysis procedure also groups women according to their ages at first birth. As one would expect, the probability of being in clusters with higher numbers (and with older ages at first birth) are strongly related to a higher level of education. The risks of being in these clusters are lower in Eastern European countries, generally characterized by a young mean age of the mother and smaller variation of ages at birth.

One of the most robust findings that arise from the literature is the positive correlation between early marriage and childbearing (the age at first birth or at first partnership) on accelerating and subsequent childbearing (Bumpass et al 1978; Finnas \& Hoem 1980). This means that the length of a given birth interval can be at least partly determined by the length of previous intervals (Heckman et al 1985). Another important set of results deals with the disturbing effect of divorce on this "engine" of childbearing. Thornton (1978) showed that for White US women marriage dissolution had no effect on the final number of children because these women had 
remarried and had lengthened their childbearing period accordingly. Thornton postulates that there exists a norm to have children in each marriage in societies where fertility is low, childbearing is planned, and where remarriage is rapid. This hypothesis was recently confirmed in the Swedish context (Vikat et al 1999). The latter study refers to a "new union commitment effect" on childbearing for couples who enter a new partnership, even with the presence of children from former unions. The age curves of fertility reveal that women with long last-birth intervals form two distinct fertility curves. This pattern is especially demonstrative for women with two and three children. In both cases, the last childbirth corresponds to the second fertility curve, whereas the first child for women with two children and the first two children for women with three children form the first fertility curve. The shapes of curves suggest the entrance into a new fertility career, which is characteristic solely for Cluster 2 . We estimate that the phenomenon increases the total number of children by about $6 \%$.

The results of the multinomial logistic regression on the probability on being in one or another cluster shows for each parity that being in Cluster 2 is associated with remarriage. This result is clear for women with 2 births, although for parities 3 and 4 the regression coefficients are not statistically significant. The results of the event-history analysis examining the influence of being in new partnership and of being in new partnership at different times during the first and the second birth interval reveal significant effects. The relative risk of giving another birth (either a second or third one) due to a new union increases sigmnificantly after 6-8 years since the previous birth. This provides evidences for the importance of a new union commitment effect.

The probability of being in Cluster 2 tends to be higher in the Baltic and Southern European countries, and this may be an indication of some influence of contraceptive failure (Philipov et al., 2004). This failure is not incompatible with the remarriage effect since remarriage increases sexual intercourse. According to this hypothesis, both effects are mixed and very difficult to disentangle without the appropriate data. These effects, however are not statistically significant for all final parities and could be also attributed to a bias due to a variation in unobservable cohabitation, non-registered in our regional data.

Many other circumstances can affect childbearing timing patterns. One of these is employment experience (for a short review, see Ram \& Rahim 1993), a point that is not addressed in this paper due to a lack of data on job careers.

Further research is required to learn more about the relationship between entering a new marriage or cohabitation and childbearing. This is of growing importance since union dissolution by separation and divorce is increasing in many countries. More detailed data and 
more research are needed for identifying the links between individual birth schedules, job careers, and other conditions. The first steps in this direction have been already taken and have returned interesting results. Bernardi and Di Giulio (2005) recently applied the methodology of this study to the more detailed data of the Italian FFS and found that, in addition to union interruptions, women from Cluster 2 are also more likely to experience job discontinuities and to receive less support from relatives.

\section{Acknowledgements}

The authors are grateful to Dmitri Jdanov and Francesco Billari for fruitful discussions at the early stages of this work. We are grateful to Jan Hoem and Jose-Antonio Ortega for helpful comments to presentations of this study. We would like to thank Susan Backer for valuable language editing of this paper.

\section{References}

Bacher J. 1996. Clusteranalyse: anwendungsorientierte. Einführung-2., erg. Aufl. - München [u.a.] : Oldenbourg, 1996

Bernardi, Laura and Paola Di Giulio (2005), "Reproductive Patterns of Italian Women: a Role for Kin Support?", presented at the Postponement of Childbearing in Europe Conference, poster session, Vienna, 1-3 December

Blossfeld Hans-Peter and Johannes Huinink. 1991. "Human capital investments or norms of role transition? How women's schooling and career affect the process of family formation". The American Journal of Sociology, 97(1), pp. 143-168.

Bumpass, L. L., Rindfuss, R., R., Janosik, R. B., 1978, “Age and Marital Status at First Birth and the Pace of Subsequent Fertility", Demography, 15, 1, 75-86

Festy, P., Prioux, F., 2001, An Evaluation of the FFS Project, INED, Paris

Finnas, F., Hoem, J. M., 1980, "Starting Age and Subsequent Births Intervals in Cohabitational Unions in Current Danish Cohorts, 1975", Demography, 17, 3, 275-295

Heckman, J. J., Hotz, V. J., Walker, J. R., 1985, "New Evidence on the Timing and Spacing of Births", American Economic Review, 75, 2, 179-184

Lutz, W. 1989. Distributional Aspects of Human Fertility: a Global Comparative Study. New York, Academic Press.

Philipov, D., Andreev, E., Kharkova, T. and Shkolnikov, V., 2004, "Induced Abortion in Russia: Recent Trends and Underreporting in Surveys", European Journal of Population, 20: 95-117,

Ram, B., Rahim, A., 1993, “Enduring Effects of Women's Early Employment Experiences on Child-Spacing: The Canadian Evidence", Population Studies, 47, 2, 307-317

Rodríguez, G., Hobcraft, J., McDonald, J., Meneen, J., Trussel, J., 1984, A Comparative Analysis of Determinants of Births Intervals, WFS Comparative Studies, International Statistical Institute, World Fertility Survey 
Shkolnikov, V. M., Andreev, E. M., Houle, R., Vaupel, J. W., 2004, The Concentration of Reproduction in Cohorts of US and European Women, Max-Planck Institute for Demographic Research, Rostock, Working Paper WP-2004-027

Solis, P. and Billari, F. 2002. Work lives amid social change and continuity: occupational trajectories in Monterrey, Mexico. MPIDR Working Paper WP-2002-009.

StataCorp., 2001. Stata Statistical Software: Release 7.0. College Station, TX: Stata Corporation.

Thornton, A., 1978, "Marital Dissolution, Remarriage, and Childbearing”, Demography, 15, 3, 361-380

Vaupel, James W. and Goodwin, Dianne G. 1987. The concentration of reproduction among US women, 1917-80. Population and Development Review, 13(4), pp. 723-730.

Vikat, A., Thomson, E., Hoem, J. M., 1999, "Stepfamily Fertility in Contemporary Sweden: The Impact of Childbearing before the Current Union”, Population Studies, 53, 2, 211-225 


\section{Annex 1. Choice of $K$ in K-means cluster analysis.}

The choice of $\mathrm{K}$ is a central methodological problem in the application of the $\mathrm{K}$-means cluster analysis. The method requires that the number of clusters be chosen in advance by the user. A conventional approach aims to identify an optimal number of clusters from various possible solutions. One way of doing this is to compare different possible solutions in light of certain statistical criteria and to evaluate which one better fits the data. This operation can be done by comparing two successive solutions over a certain range of number of clusters, up to the point at which the number of cases in the clusters becomes too low. One begins by comparing a onecluster solution with a 2-cluster solution, and then the 2-cluster solution has to be compared with the next 3-cluster solution, etc. At each step, some statistics are computed for the selection of the optimal solution.

We used two statistics for the purpose of the present analysis: the proportional reduction of errors (PRE) coefficient and the F-Max (or the pseudo-F) (Bacher, 1996). PRE compares a Kcluster solution with the previous (K-1)-cluster solution in terms of explained sums of squares within clusters $\left(S S_{\text {within }}\right)$ :

$$
P R E_{K}^{2}=1-\frac{S S_{\text {within }}(K)}{S S_{\text {within }}(K-1)}
$$

A low relative reduction of variance within clusters between the solutions with K-1 and with $\mathrm{K}$ clusters signals that the latter solution does not significantly improve clustering compared to the preceding one. This means that the K-1 solution can thus be considered optimal. F-Max is another statistics. It is based on comparing the components of the total sum of squares corresponding to variances between and within clusters $\left(S S_{\text {between }}\right.$ and $\left.S S_{\text {within }}\right)$. This measure complements the PRE coefficient for the fact that having a solution with more clusters generally results in a higher explained variance:

$$
F-M A X_{K}=\frac{S S_{\text {between }}(K) / K-1}{S S_{\text {within }}(K) / n-K}
$$

where $n$ is the total number of observations.

The user has to look for a local maximum of $F-M A X$.

None of these statistics or any other statistics, however, is totally satisfactory as they can lead to different optimal numbers of clusters. One has to take into account a very practical 
consideration: the attrition of the number of cases in each cluster when the number of clusters increases. This is a real concern for further statistical analysis.

We applied this methodology to decide on the number of clusters at each parity 2 to 4 . In fact, we used more statistics, but the two introduced above turned out to be the most useful. Figure A1-1 shows the values of PRE and F-Max for parity 2 and for nine solutions (2 to 9 clusters).

Figure A1-1. Value of PRE and F-MAX, women with 2 live births

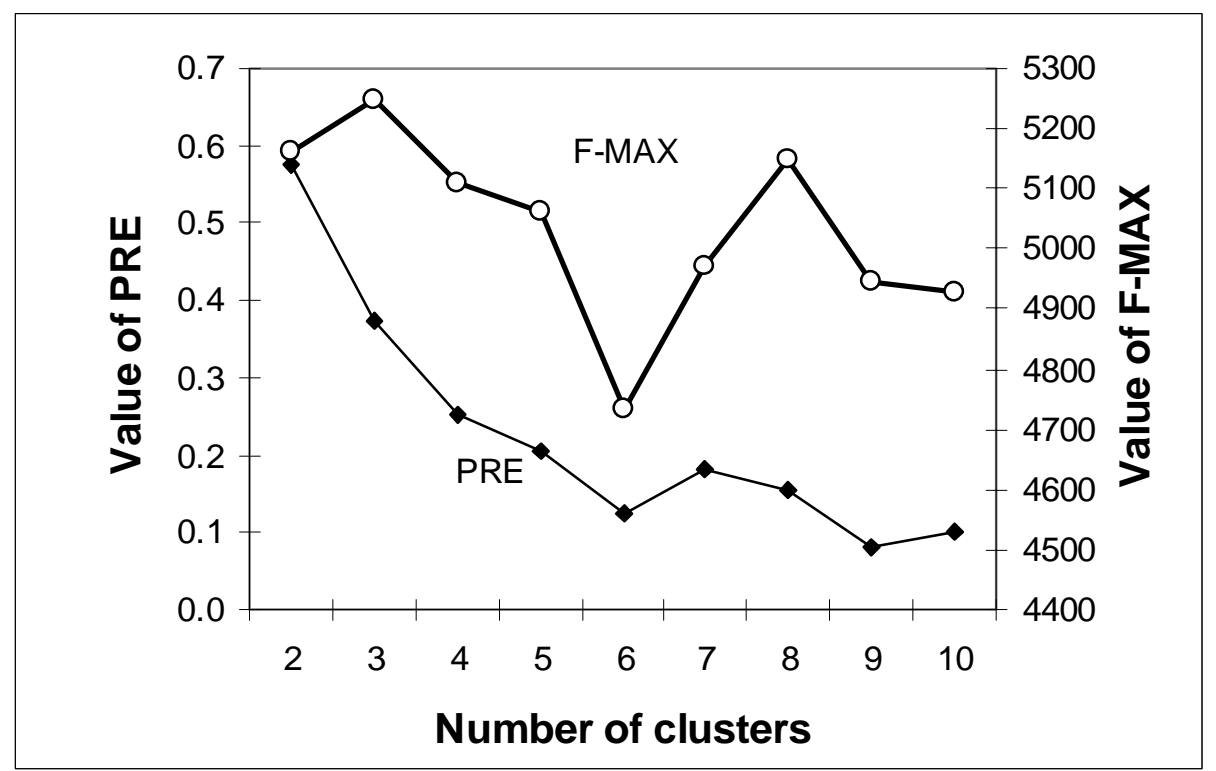

From figure A1-1, at least three solutions can be considered optimal. First, given $F-M A X$, one can easily identify two local maximums at $\mathrm{K}=3$ and $\mathrm{K}=8$. Second, following the evolution of $P R E$ values along the number-of-cluster axis, two local minimums are found at $\mathrm{K}=6$ and $\mathrm{K}=9$, and thus two optimal solutions seem to be at $\mathrm{K}-1=5$ and $\mathrm{K}-1=8$. Returning to our main analysis, the picture of birth schedules would look like figure A1-2 for these three solutions. Clearly, the solution with $\mathrm{K}=3$ does not provide much insight into the variety of existing schedules (all three displayed look much the same with only a different age at first birth). The solution with $\mathrm{K}=8$ is very interesting and adds details to the $K=5$ solution retained for the analysis in this paper. Compared to the $\mathrm{K}=5$ solution, the main point to be highlighted from the $\mathrm{K}=8$ solution is that the existence of a long last inter-birth interval replicates itself at higher age at first birth. This was shown for Italy by Bernardi and DiGiulio (2005).

But as mentioned previously, the higher the number of clusters, the lower the number of cases (women) in each cluster is. In the $\mathrm{K}=8$ solution, two clusters have less than 200 women, and this is a serious limitation for further analysis. This was the main reason for not retaining this solution over the $\mathrm{K}=5$ solution. 
Figure A1-2. Three solutions of K-means cluster analysis for women with two children.
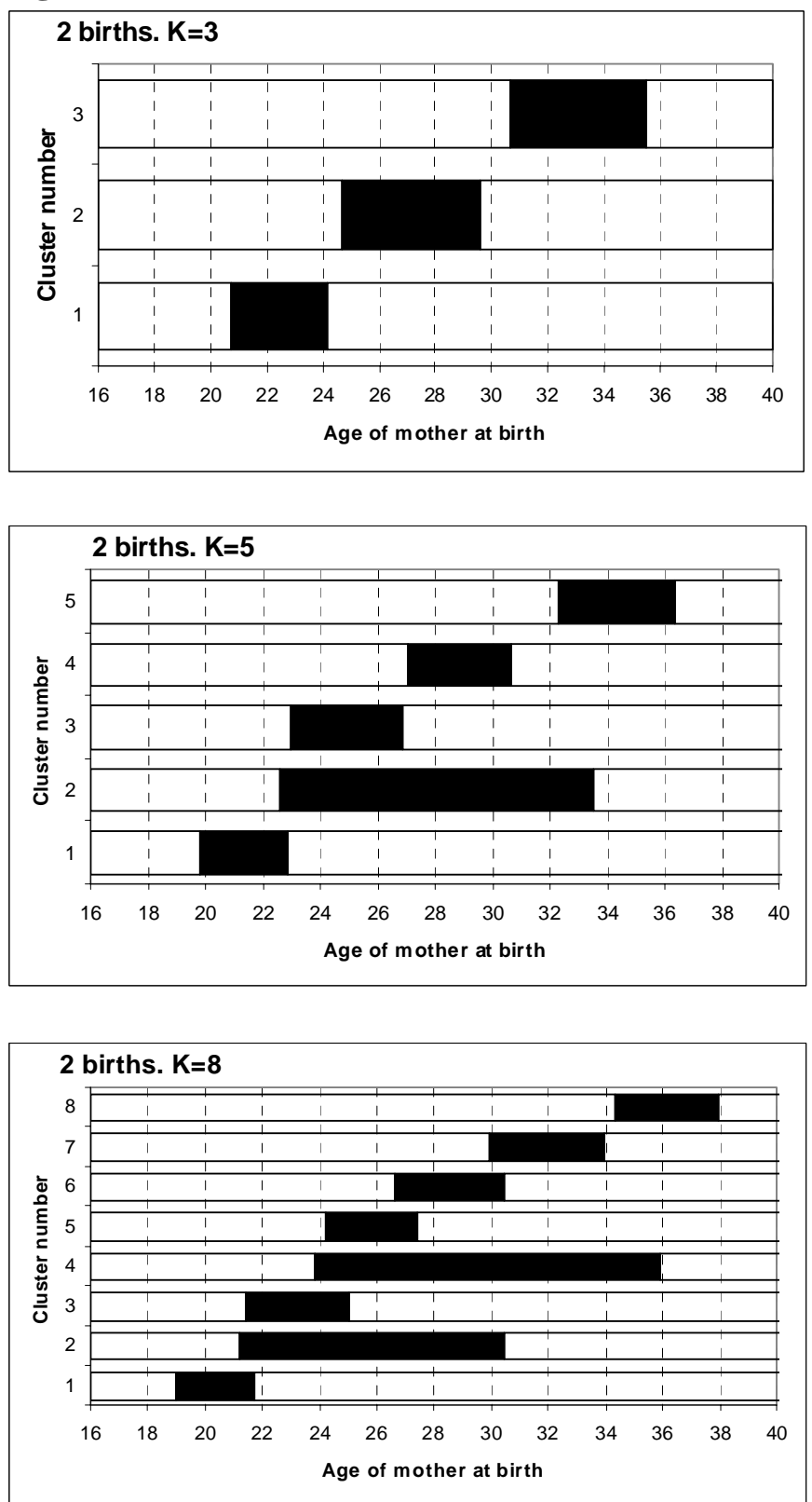


\section{Annex 2. Sensitivity to initial seeds and search for a global minimum.}

The K-means algorithm is based on the least-squares clustering procedure. The solution must correspond to the minimum of the pooled within-cluster variance. If one re-runs the K-means routine, it could return varying solutions depending on random initial seeds. It suggests that the global minimum should be assured by repeating the K-means routine with a calculation of $S S_{\text {within }}$ many times. In three experimental calculations, the routine was repeated 1,500, 1,000, 500, and 100 times on the birth schedules for clustering women with two and three children. The global minimum solution was found in all of the three experiments. Each time this solution was reached after very few K-means runs. Figure A2-1 shows 100 values of $S S_{\text {within }}$ corresponding to $100 \mathrm{~K}$-means runs. The K-means routine has returned three major solutions: 70 runs reached (or almost reached) the global minimum solution, the remaining 26 and 4 runs returned two other solutions that were substantially different from the global minimum.

Figure A2-1. $S S_{\text {within }}$ obtained in $100 \mathrm{~K}$-means runs.

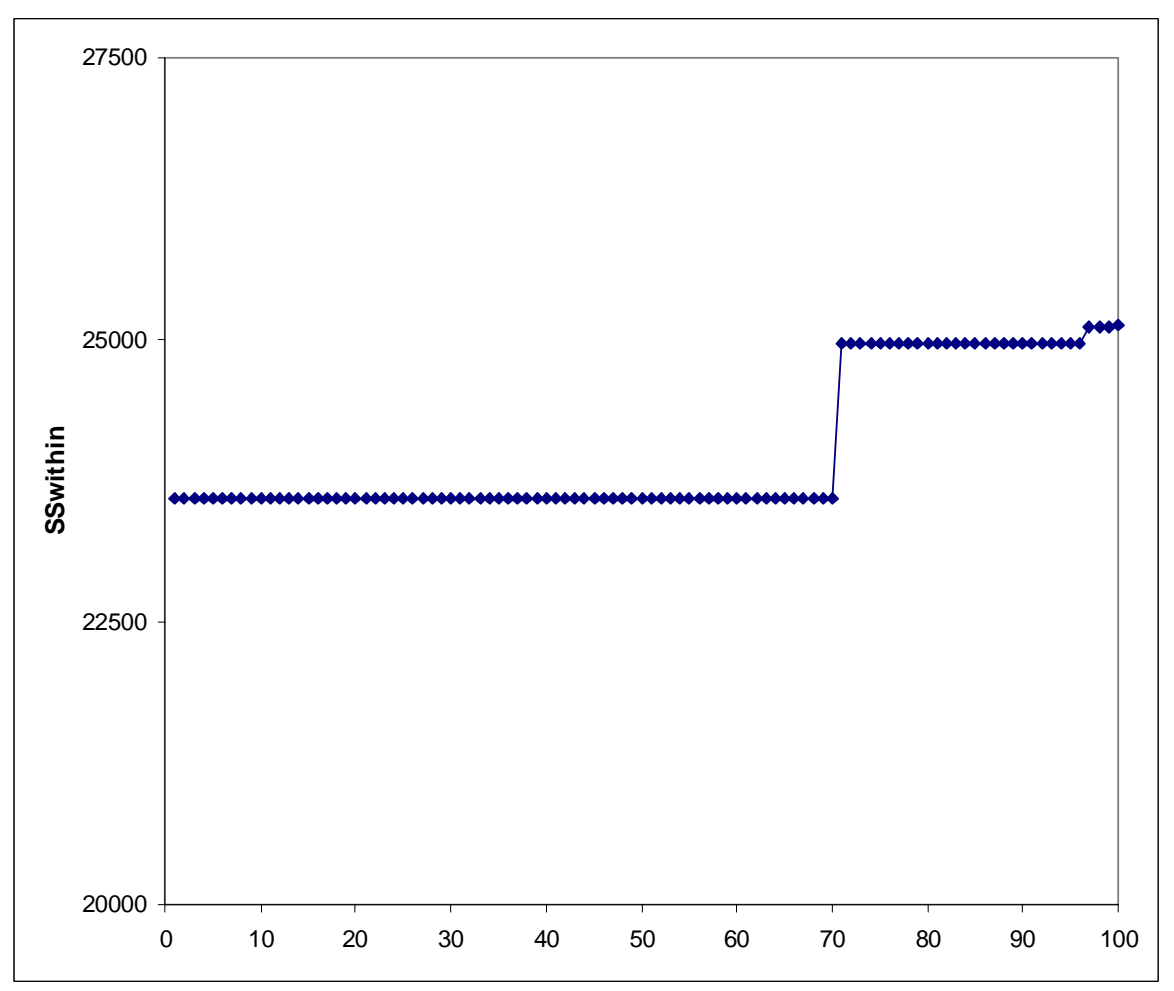

This result suggests that the clustering routine has to be repeated since a single run can return a local minimum solution. In all experimental calculations, the global minimum solution (or solutions almost identical to it) was reached in the majority (from $71 \%$ to $98 \%$ ) of runs. So, the global minimum solution can be certainly found after 100 runs.

\section{Annex 3. Outputs of the event-history regression analysis.}

Table A3-1. Effects of partnership status and education on second and third birth (conceptions) ${ }^{\#}$. Outputs of the exponential model with piecewise constant baseline hazard. 


\begin{tabular}{|c|c|c|c|c|c|}
\hline \multirow{2}{*}{ Variables } & \multirow{2}{*}{ Categories } & \multicolumn{2}{|c|}{$\begin{array}{l}\text { Transition to second } \\
\text { birth }\end{array}$} & \multicolumn{2}{|c|}{$\begin{array}{l}\text { Transition to third } \\
\text { birth }\end{array}$} \\
\hline & & $\begin{array}{c}\text { Hazard } \\
\text { Ratio }\end{array}$ & $\mathrm{P}>\mathrm{z}$ & $\begin{array}{c}\text { Hazard } \\
\text { Ratio } \\
\end{array}$ & $\mathrm{P}>\mathrm{z}$ \\
\hline Partnership status & $\begin{array}{l}\text { Not in partnership } \\
\text { First cohabitation / marriage } \\
\text { Cohabitation } 2+ \\
\text { Remarriage }\end{array}$ & $\begin{array}{r}0.31 \\
1 \\
0.89 \\
1.16 \\
\end{array}$ & $\begin{array}{l}0.000 \\
0.001 \\
0.000\end{array}$ & $\begin{array}{r}0.63 \\
1 \\
1.64 \\
1.29 \\
\end{array}$ & $\begin{array}{l}0.000 \\
0.000 \\
0.000\end{array}$ \\
\hline Education & $\begin{array}{l}\text { Less than secondary } \\
\text { Secondary } \\
\text { Tertiary }\end{array}$ & $\begin{array}{r}1.08 \\
1 \\
1.15 \\
\end{array}$ & $\begin{array}{l}0.000 \\
0.000 \\
\end{array}$ & $\begin{array}{r}1.35 \\
1 \\
1.02 \\
\end{array}$ & $\begin{array}{l}0.000 \\
0.590 \\
\end{array}$ \\
\hline & & $\begin{array}{l}\text { Hazard } \\
\text { Rate }\end{array}$ & $\mathrm{P}>\mathrm{z}$ & $\begin{array}{l}\text { Hazard } \\
\text { Rate }\end{array}$ & $\mathrm{P}>\mathrm{z}$ \\
\hline $\begin{array}{l}\text { Baseline: hazard rate } \\
\text { Years since last birth }\end{array}$ & $\begin{array}{l}0-1 \\
2-3 \\
4-5 \\
6-7 \\
8-9 \\
10+\end{array}$ & $\begin{array}{l}0.26 \\
0.33 \\
0.22 \\
0.14 \\
0.09 \\
0.03\end{array}$ & $\begin{array}{l}0.000 \\
0.000 \\
0.000 \\
0.000 \\
0.000 \\
0.000\end{array}$ & $\begin{array}{l}0.09 \\
0.09 \\
0.06 \\
0.04 \\
0.03 \\
0.01\end{array}$ & $\begin{array}{l}0.000 \\
0.000 \\
0.000 \\
0.000 \\
0.000 \\
0.000\end{array}$ \\
\hline Statistics & $\begin{array}{l}\text { No. of failures } \\
\text { Person-years at risk } \\
\text { Log likelihood } \\
\text { Wald chi2(29) } \\
\text { Prob > chi2 }\end{array}$ & $\begin{array}{c}276 \\
1782 \\
-536 \\
818 \\
0.0\end{array}$ & & $\begin{array}{r}95 \\
196 \\
-27 \\
753 \\
0.0\end{array}$ & \\
\hline
\end{tabular}

\# The effects of time-constant covariates, such as women's birth cohort (1939-49, 1950-59, 1960-69), women's age at first birth, and the country of residence are not shown.

Table A3-2. Effects of the partnership status in interaction with the baseline on second and third births (conceptions)." Outputs of the exponential model.

\begin{tabular}{|c|c|c|c|c|c|}
\hline & & \multicolumn{2}{|c|}{$\begin{array}{l}\text { Transition to second } \\
\text { birth }\end{array}$} & \multicolumn{2}{|c|}{$\begin{array}{l}\text { Transition to third } \\
\text { birth }\end{array}$} \\
\hline & & $\begin{array}{l}\text { Haz. } \\
\text { Ratio }\end{array}$ & $P>Z$ & $\begin{array}{l}\text { Haz. } \\
\text { Ratio }\end{array}$ & $P>Z$ \\
\hline \multirow{18}{*}{$\begin{array}{l}\text { Interaction term } \\
\text { Partn. status/Years since the } \\
\text { last birth }\end{array}$} & No partn/0-1 & 0.39 & 0.000 & 0.76 & 0.000 \\
\hline & No partn/2-3 & 0.23 & 0.000 & 0.50 & 0.000 \\
\hline & No partn/4-5 & 0.26 & 0.000 & 0.60 & 0.000 \\
\hline & No partn/6-7 & 0.30 & 0.000 & 0.68 & 0.004 \\
\hline & No partn/8-9 & 0.36 & 0.000 & 0.52 & 0.001 \\
\hline & No partn/10+ & 0.53 & 0.000 & 0.78 & 0.160 \\
\hline & Cohab $2+/ 0-1$ & 0.88 & 0.044 & 1.19 & 0.049 \\
\hline & Cohab 2+/2-3 & 0.66 & 0.000 & 1.47 & 0.000 \\
\hline & Cohab 2+/4-5 & 0.76 & 0.001 & 1.85 & 0.000 \\
\hline & Cohab 2+/6-7 & 1.15 & 0.127 & 2.25 & 0.000 \\
\hline & Cohab 2+/8-9 & 1.41 & 0.006 & 2.22 & 0.000 \\
\hline & Cohab $2+/ 10+$ & 1.77 & 0.000 & 4.08 & 0.000 \\
\hline & Remarr/0-1 & 0.97 & 0.726 & 1.15 & 0.081 \\
\hline & Remarr/2-3 & 0.96 & 0.607 & 1.04 & 0.716 \\
\hline & Remarr/4-5 & 1.09 & 0.374 & 1.04 & 0.788 \\
\hline & Remarr/6-7 & 1.68 & 0.000 & 1.86 & 0.000 \\
\hline & Remarr/8-9 & 1.76 & 0.000 & 2.25 & 0.000 \\
\hline & Remarr/10+ & 1.88 & 0.000 & 3.03 & 0.000 \\
\hline
\end{tabular}




\begin{tabular}{|c|c|c|c|c|c|}
\hline Education & $\begin{array}{l}\text { Less than secondary } \\
\text { Secondary } \\
\text { Tertiary }\end{array}$ & $\begin{array}{r}1.07 \\
1 \\
1.15\end{array}$ & $\begin{array}{l}0.000 \\
0.000\end{array}$ & $\begin{array}{r}1.35 \\
1 \\
1.02\end{array}$ & $\begin{array}{l}0.000 \\
0.600\end{array}$ \\
\hline $\begin{array}{l}\text { Baseline: hazard rate } \\
\text { Years since last birth } \\
\text { (first coh. / marriage) }\end{array}$ & $\begin{array}{l}0-1 \\
2-3 \\
4-5 \\
6-7 \\
8-9 \\
10+\end{array}$ & $\begin{array}{l}0.26 \\
0.34 \\
0.22 \\
0.14 \\
0.08 \\
0.02\end{array}$ & $\begin{array}{l}0.000 \\
0.000 \\
0.000 \\
0.000 \\
0.000 \\
0.000\end{array}$ & $\begin{array}{l}0.09 \\
0.09 \\
0.06 \\
0.04 \\
0.03 \\
0.01\end{array}$ & $\begin{array}{l}0.000 \\
0.000 \\
0.000 \\
0.000 \\
0.000 \\
0.000\end{array}$ \\
\hline Statistics & $\begin{array}{l}\text { No. of failures } \\
\text { Person-years at risk } \\
\text { Log likelihood } \\
\text { Number of obs } \\
\text { Wald chi2(46) } \\
\text { Prob > chi2 }\end{array}$ & \multicolumn{2}{|c|}{$\begin{array}{c}27678 \\
178273 \\
-53582 \\
352226 \\
81616 \\
0.000\end{array}$} & \multicolumn{2}{|c|}{$\begin{array}{c}9535 \\
196577 \\
-27570 \\
350839 \\
74829 \\
0.000\end{array}$} \\
\hline
\end{tabular}

\# The effects of time-constant covariates, such as women's birth cohort (1939-49, 1950-59, 1960-69), women's age at first birth, and the country of residence are not shown. 